\title{
Successful Treatment of Mutinucleate Cell Angiohistiocytoma with Nd:YAG Laser
}

\author{
Salih Mishlab1, Emily Avitan-Hersh ${ }^{1,2}$, Ziad Khamaysi ${ }^{1,2^{*}}$ \\ ${ }^{1}$ Department of Dermatology, Rambam Health Care Campus, Haifa, Israel \\ ${ }^{2}$ Technion institute of technology, Haifa, Israel \\ Email: ${ }^{\star}$ __khamaysi@health.rambam.gov.il
}

How to cite this paper: Mishlab, S., Avitan-Hersh, E. and Khamaysi, Z. (2021) Successful Treatment of Mutinucleate Cell Angiohistiocytoma with $\mathrm{Nd}: Y A G$ Laser. Journal of Cosmetics, Dermatological Sciences and Applications, 11, 38-43.

https://doi.org/10.4236/jcdsa.2021.111004

Received: November 26, 2020

Accepted: March 8, 2021

Published: March 11, 2021

Copyright (c) 2021 by author(s) and Scientific Research Publishing Inc. This work is licensed under the Creative Commons Attribution International License (CC BY 4.0)

http://creativecommons.org/licenses/by/4.0/

\begin{abstract}
A 50-year-old man had noticed the gradual appearance of asymptomatic skin lesions on the dorsal aspects of the hands during the last 3 years. Physical examination revealed clusters of multiple purplish dome-shaped infiltrated papules. Histopathological examination was compatible mutinucleate cell angiohistiocytoma. We treated him with $10,464 \mathrm{~nm}$ Nd:YAG laser, after the second session, some of the lesions had disappeared completely while the rest has gained substantial improvement. There were no adverse reactions and no recurrence after two years of follow-up. MCAH is a rare vascular fibrohistiocytic proliferation. No standard of care exists. We believe that Nd:YAG laser should be considered the treatment of choice.
\end{abstract}

\section{Keywords}

Mutinucleate Cell Angiohistiocytoma, Laser Therapy,

Nd:YaG-Neodymium-Doped Yttrium Aluminum Garnet

\section{Introduction}

Mutinucleate cell angiohistiocytoma is a rare, vascular, fibrohistiocytic proliferation [1]. The course tends to be progressive but benign [2]. The tumor presents as asymptomatic grouped red-to-violaceous papules, developing over weeks to months, which have a predilection for the dorsum of hands and lower extremities [2]. However, Localized, multifocal, and generalized variants have been reported [3], the localized variant is most common and best-described. There is a female predominance with a ratio of 3:1 [4]. The etiology is unknown and these lesions arise as a reactive rather than a neoplastic process [4]. Several reports of spontaneous remission further support the reactive hypothesis. Another theory suggests the influence of female hormone, due to the expression of estrogen re- 
ceptor (ER) on the interstitial and multinucleate cells of the lesions [5]. This theory may also explain why MCAH occurs more frequently in women [5]. There is an a continuous debate whether MCAH represent a histological variant of dermatofibroma [6], as there is a significant histopathologic overlap, thus, the diagnosis requires an experienced pathologist and a careful clinic-pathological correlation. Treatment is not mandatory but may be desired by patients for cosmetic reasons. No standard of care exists. Treatment options include: intralesional corticosteroids, surgical excision, cryotherapy, and lasers (Argon, PDL and $\mathrm{CO}_{2}$ lasers [7]. These treatments have all shown anecdotal efficacy. Nd:YAG laser offers the combined efficacy of targeting deep seated vessels and limited melanin absorption, which enhances its influence on deep vascular proliferations, with less pigment alterations, respectively. We describe a case of Mutinucleate cell angiohistiocytoma treated with Nd:YAG laser with a satisfactory result and no recurrence after two-year follow up.

\section{Case Presentation}

A 50 y/o male dentist with Fitzpatrick skin type IV with no relevant medical history and no family history of similar dermatological conditions reported the gradual appearance of asymptomatic skin lesions on the dorsal aspects of the hands during the last 3 years. There was no preceding trauma. His physical examination (Figure 1(a)) revealed clusters of multiple purplish dome-shaped infiltrated papules without scale, on dorsa of hands. Histopathological examination of a 4-mm punch biopsy specimen from the dorsal hand showed epidermal acanthosis within the superficial to mid reticular dermis was a proliferation of haphazardly arranged capillaries and small venules with angulated polygonal multinucleate giant cells embedded within a collagenous fibrotic stroma (Figure 2(a), Figure 2(b)). A mixed perivascular infiltrate, composed predominantly of lymphocytes was also present. Vascular endothelial cells were highlighted by antibodies against CD31. Additionally, a marker for lymphatic vessels D2-40 and a marker for HHV8 (LANA1) were negative.

The patient was diagnosed with MCAH given the peculiar clinical and histopathological findings.

Topical corticosteroids therapy was ineffective. We treated him with 2 monthly sessions of Nd:YAG laser using a $1064 \mathrm{~nm} \mathrm{Nd:YAG} \mathrm{laser}\left(3 \mathrm{~mm}\right.$ spot, $240 \mathrm{~J} / \mathrm{cm}^{2}$ and $40 \mathrm{msec}$ ), on the dorsa of hands. After the second session, the patient reported subjective improvement in terms of thickness and color and examination revealed the lesions were paler, more flattened and less infiltrated. After the second session, some of the lesions had disappeared completely while the rest has gained substantial improvement (Figure 1(b)). The patient had a mild discomfort during the treatment. Treatment was stopped after 2 sessions based on the patient's satisfaction with treatment results. But in the future, more sessions will be considered.

There were no adverse reactions such as scarring, bleeding after 2 years of follow-up. 


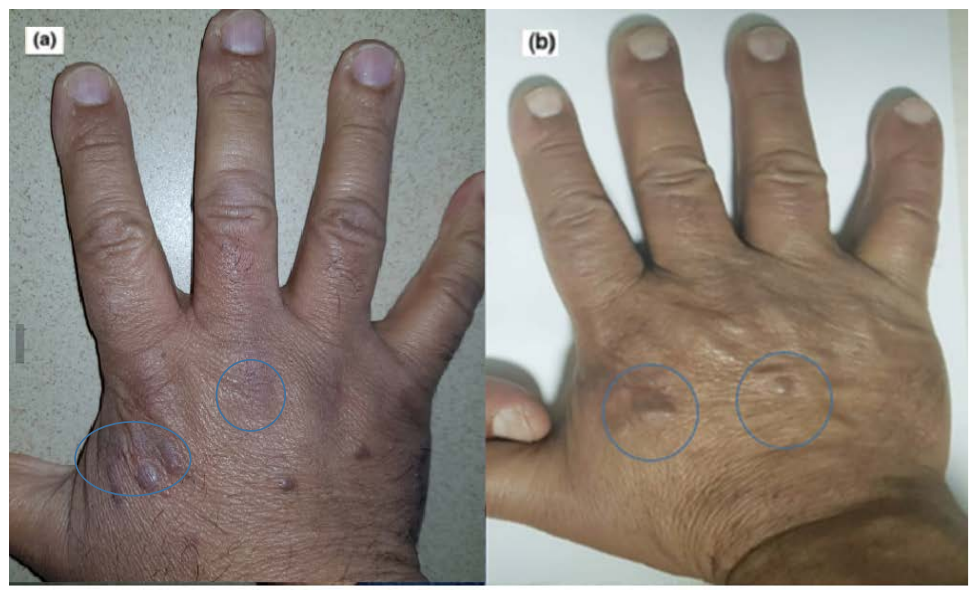

Figure 1. (a) purplish papular lesions corresponding to untreated MCAH lesions on hand dorsum. (b) Near complete resolution of the above $\mathrm{MCAH}$ lesions after two sessions of Nd:YAG laser. There is no visible scarring.

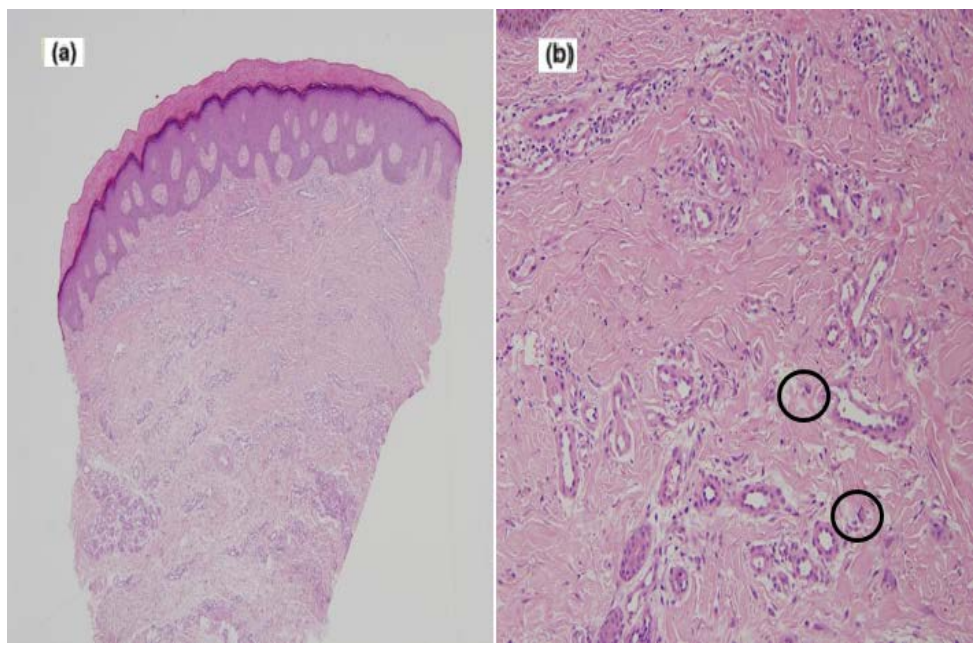

Figure 2. (a) Low-power view showing epidermal hyperplasia, and proliferation of poorly grouped capillaries and small venules in the superficial and mid dermis $(\mathrm{H} \& \mathrm{E}, \times 10)$. (b) Higher magnification showing capillaries and venules with scattered multinucleate giant cells (black circles) within a collagenous fibrotic stroma $(\mathrm{H} \& \mathrm{E}, \times 40)$.

\section{Discussion}

Mutinucleate cell angiohistiocytoma is a relatively new entity with a few hundred cases reported so far [1] [2] [3] [4]. There is no clear understanding of the etiology of the MCAH [5] [6] and it has been categorized as connective tissue disorder or vascular neoplasia in literature. Meanwhile, surgical approach remains as the definitive therapeutic method in MCAH [7]. Laser therapy is reported to result in clinical resolution of the lesions without scarring in comparison with surgical excision [7]. They are difficult to manage due to their number and deep seated location. Previous reports regarding treatment with argon laser are partially supportive of this treatment [8] [9] in part because of the depth of 
penetration of argon laser is only $500 \mu \mathrm{m}$ to target deep seated MCAH lesions in the mid or deep reticular dermis. In such cases, as in our case, pre-treatment biopsy showed proliferation of vessels in the papillary and mid dermis with moderate degree of dermal fibrosis. In another report of treatment using PDL in a patient with a 5-year history of multiple MCAH papules on the thighs and calves had merely shown mild improvement, these lesions showed slight vascular proliferation and dermal fibrosis before treatment [10].

Kopera et al. [7] reported the successful use of the argon laser to treat 2 patients with a 2- to 3-year history of MCAH. Lesions were located on the face and hands. Increased vascularity in the mid dermis with normal epidermis was noticed. Dermal fibrosis was not reported. Laser treatment yielded flattening of the lesions with no scarring at 8 weeks and no recurrence after 1 year. However, Coco et al. [9] reported on a patient with a 5-year history of multiple papules on the lower extremities. Lesions showed proliferation of vessels in the papillary and mid dermis with moderate degree of dermal fibrosis. Treatment with argon laser was unsuccessful. In addition, IPL laser has been reported as a definitive treatment in 2 cases [11]. Lesions appeared as papules on the nose and back with a 3-year history in 1 case. Lesions in either case had increased vascularity without fibrosis. Complete resolution was achieved in both cases, with residual hyperpigmentation reported in 1 case. Väkevä et al. [12] reported treatment of 2 cases of MCAH with the $\mathrm{CO}_{2}$ laser. These lesions were present for 6 months to a year and showed increased vascularity in papillary and mid dermis with slight hyperkeratosis in the epidermis and sparse fibrohistiocytic cell infiltration. No relapse was noted at 2.5- or 5-month follow-up.

Whereas Argon laser, PDL, and IPL specifically target the increased superficial vascular component in MCAH lesions, without much influence on the fibrous stroma or the ablation of deep seated vascular proliferations, A deeply penetrating vascular-targeting $1064 \mathrm{~nm} \mathrm{Nd}$ :YAG laser with limited absorption by melanin, enhances the ability to target the deeper vascular lesions, while maintaining a safety profile in our patient with darker skin phenotype. To our knowledge, we are first to describe a patient with MCAH treated with Nd:YAG laser. We obtained satisfactory results for our patient with no recurrence after two-year follow up.

\section{Conclusion}

Based on our experience, we believe that Nd:YAG laser should be considered the treatment of choice in patients with mutinucleate cell angiohistiocytoma where other treatment options might cause discomfort, dyspigmentation or scarring complications.

\section{Author Contribution}

All authors participated in patient care, obtained patient history and workup, and wrote the manuscript 


\section{Abbreviations}

$\mathrm{Nd}$ YaG, neodymium-doped yttrium aluminum garnet; IPL, intense pulsed light; MCAH, multinucleate cell angiohistiocytoma; PDL, pulsed dye laser.

\section{Informed Consent}

The patient gave informed consent.

\section{Conflicts of Interest}

The authors declare no conflicts of interest regarding the publication of this paper.

\section{References}

[1] Smith, N.P. and Wilson Jones, E. (1985) Multinucleate Cell Angiohistiocytoma: A New Entity. British Journal of Dermatology, 113, 15. https://doi.org/10.1111/j.1365-2133.1985.tb12966.x

[2] Jaconelli, L., Kanitakis, J., Ktiouet, S., Faure, M. and Claudy, A. (2009) Multinucleate Cell Angiohistiocytoma: Report of Three New Cases and Literature Review. Dermatology Online Journal, 15, 4.

[3] Frew, J. (2015) Multinucleate Cell Angiohistiocytoma: Clinicopathological Correlation of 142 Cases with Insights into Etiology and Pathogenesis. The American Journal of Dermatopathology, 37, 222-228.

https://doi.org/10.1097/DAD.0000000000000075

[4] Wilson, J.E., Cerio, R. and Smith, N.P. (1990) Multinucleate Cell Angiohistiocytoma: An Acquired Vascular Anomaly to Be Distinguished from Kaposi's Sarcoma. British Journal of Dermatology, 122, 651-663. https://doi.org/10.1111/j.1365-2133.1990.tb07287.x

[5] Cesinaro, A.M., Roncati, L. and Maiorana, A. (2010) Estrogen Receptor Alpha Overexpression in Multinucleate Cell Angiohistiocytoma: New Insights into the Pathogenesis of a Reactive Process. The American Journal of Dermatopathology, 32, 655-659. https://doi.org/10.1097/DAD.0b013e3181d3ca49

[6] Doshi-Chougule, B.N., Gust, A., Mentzel, T. and Böer-Auer, A. (2013) Multinucleate Cell Angiohistiocytoma with Hypertrophic Nerves. Journal of Cutaneous Pathology, 40, 1048-1053. https://doi.org/10.1111/cup.12227

[7] Kopera, D., Smolle, J. and Kerl, H. (1995) Multinucleate Cell Angiohistiocytoma: Treatment with Argon Laser. British Journal of Dermatology, 133, 308-310. https://doi.org/10.1111/j.1365-2133.1995.tb02636.x

[8] Sass, U., Noel, J.C., André, J. and Simonart, T. (2000) Multinucleate Cell Angiohistiocytoma: Report of Two Cases with No Evidence of Human Herpesvirus-8 Infection. Journal of Cutaneous Pathology, 27, 258-261.

https://doi.org/10.1034/j.1600-0560.2000.027005258.x

[9] Coco, V., Guerriero, C., Di Stefani, A., Pennacchia, I. and Peris, K. (2016) Linear and Bilateral Multinucleated Cell Angiohistiocytoma (MCAH). Journal of Dermatological Case Reports, 10, 58-61. https://doi.org/10.3315/jdcr.2016.1237

[10] Applebaum, D.S., Shuja, F., Hicks, L., Cockerell, C. and Hsu, S. (2014) Multinucleate Cell Angiohistiocytoma: A Case Report and Review of the Literature. Dermatology Online Journal, 20, Article ID: 22610.

[11] Fernández-Jorge, B., del Pozo, J., García-Silva, J., Barja, J.M., Yebra-Pimentel, M.T. 
and Fonseca, E. (2009) Multinucleate Cell Angiohistiocytoma: Treatment Using Intense Pulsed Light. Dermatologic Surgery, 35, 1141-1143.

https://doi.org/10.1111/j.1524-4725.2009.01203.x

[12] Väkevä, L., Saksela, O. and Kariniemi, A.L. (2003) Multinucleate Cell Angiohistiocytoma: A Report of Four Cases in Finland. Acta Dermato-Venereologica, 83, 222-223. https://doi.org/10.1080/00015550310007265 